\title{
Perfil académico y de empleabilidad de los graduados de Antropología Aplicada de la Universidad Politécnica Salesiana
}

\section{Academic and employability profile of the Applied Anthropology graduates of the Salesian Polytechnical University}

\author{
Hernán Hermosa Mantilla ${ }^{1}$ \\ ohermosa@ups.edu.ec
}

José E. Juncosa ${ }^{2}$

jjuncosa@ups.edu.ec

Eloy Alfaro Reyes ${ }^{3}$

zancudoirreverente@hotmail.com

\begin{abstract}
Resumen
Se estima que los antropólogos graduados en la Universidad Politécnica Salesiana adquieren una formación humanista que les motiva involucrarse en procesos donde se interrelaciona la práctica con la academia. Este artículo busca desentrañar la situación del antropólogo en los diversos espacios laborales de la sociedad ecuatoriana a través de entrevistas a sus protagonistas, la socialización y encuestas con estudiantes de la Carrera en sus últimos niveles, así como la interpretación de sus resultados para relacionarlos en conjunto. Esta investigación, a partir del proyecto de Empleabilidad de graduados de Antropología Aplicada, fue posible en el marco de los Fondos Concursables de la Universidad Politécnica Salesiana, con el ánimo de encontrar fortalezas y requerimientos para el proceso de formación académica del nuevo antropólogo.
\end{abstract}

\section{Palabras clave}

Antropología Aplicada, Universidad Politécnica Salesiana, antropólogo, Academia, graduados, estudiantes.

Forma sugerida de citar: Hermosa Mantilla, Hernán, Juncosa, José E., \& Alfaro Reyes, Eloy (2017). Perfil académico y de empleabilidad de los graduados de Antropología Aplicada de la Universidad Politécnica Salesiana. Universitas, $X V(26)$, pp. 135-162.

1 Doctor en Ciencias Internacionales de la Universidad Central del Ecuador. Docente en las Carreras de Antropología Aplicada y Educación Intercultural Bilingüe de la Universidad Politécnica Salesiana Orcid: http://orcid.org/0000-0002-7911-4718.

2 Antropólogo de la Universidad Politécnica Salesiana. Doctor (c) en Estudios Culturales Latinoamericanos en la Universidad Andina Simón Bolívar. Vicerrector de la UPS, sede Quito Orcid: http:// orcid.org/0000-0001-6926-8214.

3 Antropólogo de la Universidad Politécnica Salesiana. Magister en Antropología Social de la Facultad Latinoamericana de Ciencias Sociales, FLACSO-Ecuador. 


\begin{abstract}
It is expected that the anthropologists graduated from the Universidad Politécnica Salesiana acquire a humanist formation which motivates them to involve themselves in processes where the praxis is interrelated with academia. This article seeks to unravel the situation anthropologist at various work places Ecuadorian society through interviews with the protagonists, socialization and surveys with students of the School in its last levels and the interpretation of their results to relate together. This research project from Employability of graduates from Applied Anthropology was possible under the Competitive Funds of the Salesian Polytechnic University, with the aim of finding strengths and requirements for the process of formation of the new academic anthropologist.
\end{abstract}

Keywords

Applied Anthropology, Salesian Polytechnical University, anthropologist, Academy graduates students.

\title{
Introducción
}

Hablar de Antropología en el Ecuador es mirar los procesos sociales que ha vivido este país en cuarenta años, donde antropólogos y antropólogas acompañan diversas iniciativas como una forma de ejercicio profesional. Es una particularidad de esta ciencia social en el Ecuador que no está alejada de la historia de otras realidades en el continente. Este estudio no es un balance de logros y fracasos durante estas décadas, sino un acercamiento al momento que vive la Antropología con protagonistas fundamentales como el Estado y las organizaciones sociales. Es importante conocer si los enfoques, las orientaciones o conceptos que motivaron el surgimiento de esta ciencia en el ámbito ecuatoriano han cambiado o se mantienen, y bajo qué criterios u orientaciones lo hacen. Sobre todo interesa conocer si el sujeto social de la Antropología ha cambiado. Para este estudio se realizaron entrevistas a los profesionales antropólogos con diversas experticias en su trabajo, artistas, especialistas religiosos, funcionarios públicos, académicos y dirigentes. De esta variedad temática buscamos una interpretación del antropólogo y sus aportes más reconocidos en el proceso de formación que sean de utilidad en la vida profesional. Metodológicamente, nos acercamos a los antropólogos 
y antropólogas que trabajan en diversos espacios de la sociedad ecuatoriana. Buscamos comprender cómo se entiende a la antropología desde diversos espacios.

Complementariamente, en el transcurso de 2013 y 2014, se realizaron varias encuestas a estudiantes de los últimos niveles de Antropología Aplicada de la Universidad Politécnica Salesiana, con el ánimo de conocer los aportes que el proceso de formación provee, las dificultades encontradas y las posibilidades de mejorar, sin que estos instrumentos dejen fuera aspectos relativos al rol de los profesores y sus aportes. Paralelamente a esto se analizó la base de datos de graduados y los trabajos de grado de esta carrera. En el aspecto bibliográfico se contó con estudios sobre la realidad de la carrera de Antropología de la PUCE, memorias de encuentros y foros referidos al tema, en especial el tema abordado por la Revista Alteridades de la Universidad Iztapalapa de México.

\section{Los debates epistemológicos en el Sur y el surgimiento de la Antropología en Ecuador}

El desarrollo de la antropología latinoamericana en las últimas décadas (Krotz, 2007, p. 41) se sustentan en el surgimiento de las antropologías "segundas" que marcan distancia con las antropologías "en" el Sur y "del” Sur. Considerando que la antropología es una secuencia de paradigmas, su desarrollo empieza con el evolucionismo del siglo XIX, con las "escuelas" o "teorías" hasta los tiempos actuales de los enunciados teóricos donde observamos una dinámica antropológica como proceso en construcción, aun cuando, a pesar de los evidentes avances, siempre debamos recurrir a los "clásicos" de siempre. Se dicen "segundas" a las antropologías diferentes a la surgida en Europa del siglo XIX, y que, a pesar de sus antecedentes comunes, se caracterizan por su proceso de difusión. Pero la presencia de esta antropología en nuestra región, a diferencia de lo que podríamos imaginar, se debe a los mismos investigadores originarios que vinieron en busca de "los otros" a esta parte del mundo.

En la década de los ochenta, donde se vive la descolonización de muchos países africanos y asiáticos, esta antropología originaria empieza a establecerse en esta parte del continente para motivar la investigación antropológica y la publicación de libros especializados. (Krotz, 2007, pp. 41-44). 
La Antropología se desarrolla en nuestro continente con una orientación distinta a la que se da en Europa. A lo largo del siglo XX, esta ciencia social va apareciendo producto de diversos procesos y necesidades en cada región. La definición del objeto de estudio muta con mucha frecuencia, porque a diferencia de otras ciencias, en Latinoamérica, la Antropología no tiene un sujeto de estudio único. Esto genera un reto epistemológico importante que tiene que ver incluso con una separación profunda con el pensamiento occidental. El establecimiento de la Antropología como disciplina científica se produce en el entrecruzamiento de dos procesos nunca antes vistos.

Uno es la expansión a escala planetaria de una sola civilización en la que se conjugan nacionalismo y militarismo, misión cristiana y racismo, búsqueda capitalista de mercados y de materias primas y el otro un afán de inventariar todos los fenómenos del globo terráqueo. Uno de los cambios resultantes de más de un siglo de dominación mundial del modelo civilizatorio noratlántico, consiste en el hecho que en este Sur, tradicionalmente el hábitat principal de los objetos de estudio de la ciencia antropológica, se arraigó la antropología y cobró vida propia (Krotz, 1993, p. 5).

Esa vida propia de la que habla el autor es también la construcción de fronteras. Límites que demarcan lo que fue esa ciencia en una geografía y lo que es en otra. La Antropología es dueña de su propia vida y derroteros en este continente. Es hasta cierto punto, una Antropología con vida sincrética. Mestiza quizá, pero propia. Como quiera que sea, cada vez es más evidente esa frontera que la define y ubica. Pero así como está clara la frontera, también es más visible el camino y las diferencias. Al analizar el desarrollo de esta ciencia social, encontramos que la academia es la matriz originaria de las antropologías en nuestro continente. A ella debemos, por tanto, muchas de las realidades epistemológicas de esta ciencia (aciertos y derroteros) en este continente. En ella recayó toda la responsabilidad del desarrollo del pensamiento y la formación de otros y otras que continúen creando y desarrollando pensamientos. Sin embargo, en muchos casos, es poco o nada permeable a influencias de su propio entorno a menos que no sean aquellas nacidas en su propia matriz (Krotz, 1993).

Por más que a veces se agrega un curso de "pensamiento antropológico latinoamericano" a los cursos de "teoría antropológica", los primeros no dejan de privilegiar de modo tal la situación de "reflejo", "extensión" o "adaptación” que se pierde de vista cualquier perfil propio de las antropologías del 
Sur. Todavía está por verse en qué medida, la durante muchos años frecuente impugnación de la antropología generada en el Norte como ciencia "burguesa" e incluso "imperialista", contribuyó a esta restringida visión de las cosas, sólo en pocos casos se produjeron críticas detalladas y cuando se intentaban, solían tener como punto de referencia determinadas corrientes de pensamiento generadas en los mismos países del Norte de los cuales provenía el objeto de la crítica. Las antropologías del Sur no son reductibles a meras "extensiones" o "réplicas" (acaso imperfectas) de un modelo antropológico original. La Academia en este continente, frente a las academias "del mundo desarrollado" es vista como subalterna. "La línea de pensamiento dominante parece ser la exigencia de que los científicos de los países periféricos aporten datos y los de los países centrales tengan la exclusividad en la construcción de la teoría (Vázquez, 1993, p. 48).

A partir de lo revisado, está claro que el de la academia y su interés en crear un pensamiento propio, es un tema escabroso para la comunidad de cientistas sociales y para los profesionales que ejercen esta ciencia por fuera de los rigores académicos. En especial cuando tratamos de responder a la pregunta dónde radica la Antropología en nuestro continente. Muchos de los centros académicos donde se enseña Antropología, asumen la realidad de sus países desde una lectura particular, propia, que en ocasiones se vuelve innegociable, verdadera y "única voz calificada".

Las observaciones más recurrentes que se hacen a la academia en este continente, es que no ha sido capaz de sustituir las teorías originarias de la antropología del cuerpo de sus procesos formativos. En esto la revista mexicana Alteridades, en momentos distintos 1993 y 2010, da cuenta a manera de balance que a lo largo de las academias en América Latina se continúa estudiando las teorías y los principios de la Antropología clásica. Malinowski, Boas, Spencer, entre otros son parte de los currículos. Esto puede ser interpretado como una carencia, pero en ciencias sociales, las relaciones entre las posiciones teóricas son más bien de tipo dialéctico, hecho en el cual se basa también, a diferencia de las ciencias llamadas exactas o naturales, la existencia de "clásicos" a los cuales se puede regresar desde perspectivas distintas. No es el clásico en sí, como originario de un continente que dominó, sino las categorías interpretativas, las herramientas para la misma, así como la cercanía o conocimiento de la realidad, para que la interpretación sea un aporte, lo que le da la validez al enfoque académico. Lo que caracteriza a las 
academias de ciencias sociales en nuestro continente son las diversas maneras de hacer Hermenéutica.

La consolidación de la Antropología en tanto aporte al pensamiento en este continente, incluyó diversas maneras de conceptualizar y entender al "otro", como alter al cual conocer.

Krotz (1993) sostiene:

El otro es la hegemonización de un único tipo de conocimiento, caracterizado por una determinada organización social de sus practicantes y por el consenso en el seno de éstos acerca de ciertos procedimientos para generar y validar enunciados sobre la realidad empírica. Una de las características que a primera vista distinguen a la antropología "clásica" de la que se practica en el Sur es que en el ámbito de esta última los estudiosos y los estudiados son ciudadanos del mismo país. También son afectados (no de la misma manera) por decisiones políticas y económicas emanadas de las instituciones públicas, crea un vínculo entre intereses profesionales e intereses sociales y políticos muy diferentes que el que puede darse en el caso de un investigador visitante. Puede suponerse que el origen sociocultural (estrato socioeconómico, religión, región, etnia, incluso género) de los autores de trabajos antropológicos influye de modo diferente sobre inicio, desarrollo y resultado de una investigación cuando éstos están bajo los efectos del mismo sistema que quienes estudian, que cuando estos últimos viven en condiciones totalmente distintas que los investigadores venidos de lejos (p.11).

Los profesionales antropólogos y en algunos casos, algunas academias, asumen un rol de compromiso con su entorno social, lo hacen asumiendo conceptos y enfoques que justifican la orientación de la formación o la práctica profesional. Es decir esta ciencia cumple un rol de herramienta para la generación de compromisos por revertir la situación social observada. Se rompe así el criterio de objetividad, la separación de sujeto-objeto que caracteriza al pensamiento científico. En nuestro continente encontramos que los antropólogos y antropólogas han estado vinculados a todo tipo de procesos de cambio, algunos radicales, la lucha armada (en Colombia el Comandante de las FARC, en Perú dirigiendo el frente urbano del MRTA), y procesos sociales emergentes como en Ecuador y Bolivia ocupando dirigencias indígenas o denunciando la opresión. Ser antropólogo en este continente, gira alrededor del interés por la propia sociedad nacional y su conformación, por las condiciones sociales de quienes estudian, y por la repercusión de sus conceptos. Realiza su trabajo a la luz de la conciencia social de que es al 
mismo tiempo ciudadano e investigador, casi juez y parte de una realidad. Esa conciencia ciudadana, este percibirse como investigador-ciudadano, enmarca sus relaciones y producciones. La Antropología del debate, como la llamó Arocha, se caracterizó por repudiar la neutralidad política, rechazar el concepto de aculturación y darle prioridad al compromiso con los grupos de base (Jimeno y Arias, 2011, pp. 27-44).

\section{La Antropología en Ecuador. Lucha, consolidación y compromiso social}

En el Ecuador la Antropología surge a inicios de la década de los años setenta, hasta entonces el país no formaba sus propios profesionales y ahí radica la diferencia. Desde entonces hasta acá, el número de profesionales se estima que no superan los mil. Esta disciplina social surge en la Universidad Católica donde se formaron buena parte de los antropólogos de ese tiempo. A inicios de los años noventa, veinte años después en la Universidad Politécnica Salesiana se funda la escuela de Antropología Aplicada. Estas dos carreras de pregrado, surgen en momentos con coyunturas sociales complicadas. En el primer caso, el país está pasando de un modelo agrario a primario exportador y una industrialización forzada acompañada de Reforma Agraria, que pone en movimiento aparatos sociales diversos en todo el país. En el otro caso, el movimiento indígena encabeza una efervescencia social que interpela al Poder y los modelos económicos que pretenden cercar al Estado y dominarlo. Si bien las coyunturas son semejantes por el tipo de actor presente, los enfoques de estas dos universidades son diferentes. En la actualidad también oferta Antropología la Universidad San Francisco de Quito.

Esta ciencia social no es ni ha sido de interés para el Estado. Sólo en una ocasión se abrió la carrera de Antropología en la Universidad Estatal de Cuenca, y la formación en Arqueología en la Politécnica del Litoral se terminó cerrando. La Facultad Latinoamericana de Ciencias Sociales (FLACSO) desde inicios del noventa forma antropólogos a nivel de postgrado. Ese es el resumen de la oferta académica de este país, con ausencia de política pública en este tema. A diferencia de los otros países de la región, el Ecuador no tiene formación en la universidad pública. Las dos Universidades de pregrado, son religiosas católicas. A continuación se resume y parafrasea el 
acercamiento histórico que hace Fernando García (profesor de FLACSOEcuador) acerca de esta ciencia social a partir de una entrevista y bibliografía complementaria (García, 2011).

La Antropología ecuatoriana desarrolló dos temas: los estudios de diversidad cultural y étnica y los relacionados con la etnohistoria mesoamericana y andina, que la van a vincular con la Antropología mexicana. Cada uno de ellos requiere un tratamiento por separado, sin embargo, la relación que se establece entre ambas antropologías tiene un doble vínculo mediante la formación de profesionales ecuatorianos en México desde finales de los sesenta y de la creación del primer Departamento de Antropología en la Universidad Católica del Ecuador, en 1971. En realidad, tanto Palerm desde México, a través del CISINAH, como Murra desde los Andes, a través del Instituto de Estudios Andinos, se convirtieron en los animadores de la investigación etnohistórica de ambas realidades; dio como resultado la formación de grupos de investigadores locales, que fueron importantes contribuciones a la antropología de los dos países.

Hay un tema que surge desde los Andes como un aporte propio de la antropología ecuatoriana: la reflexión sobre historia y antropología, con el aporte inicial de Murra (1975) y su modelo de control vertical de un máximo de pisos ecológicos, y su posterior aplicación a la propuesta de control microvertical de Salomon (1980) en los Andes del Norte (actual Ecuador). Desde un punto de vista más metodológico hay otro tema que sobresale desde el inicio de la enseñanza de la antropología: la importancia de la realización del trabajo de campo y del uso de las fuentes históricas como pilar fundamental de la formación de los estudiantes. La influencia de Palerm y Murra en este enfoque es evidente. Tal como lo señala Moreno Yáñez (2008), la Antropología ecuatoriana, al igual que otras antropologías latinoamericanas, muestran influencias de cinco paradigmas operantes: la escuela estructuralfuncionalista, de inspiración británica; el estructuralismo levistraussiano, diversas modalidades del marxismo, el culturalismo angloamericano y el interpretacionismo geertziano (p. 66).

Hasta ahí el aporte de Fernando García. Una primera reflexión relaciona producción académica y contexto político; la primera y la tercera etapa se desenvolvieron en periodos de cambio e inestabilidad política profunda; la tercera especialmente es una época de gran producción y creación de instancias de formación académica antropológicas, lo cual muestra que una gran dinámica social es generadora de reflexión y producción. La segunda fase corresponde al periodo político más estable, lo que propició y garantizó la 
posibilidad de la institucionalización de la disciplina y de las instancias de formación. Una de las características de la práctica de las ciencias sociales en Ecuador, incluida la antropología, es ser parte activa de los procesos sociales y políticos; es difícil que se conciba esa práctica como una actividad estrictamente "académica", desligada de la realidad de los principales movimientos sociales y políticos. García hace una afirmación importante respecto a la profesión, y es su vinculación a procesos sociales. No se puede hablar o entender la antropología en este país sin entender el compromiso de quienes la practican con el entorno social y político que le rodea. Claro que esto ha tenido una serie de implicaciones en la práctica profesional de las décadas 80, 90 y 2000 (proyectos de desarrollo con orientaciones y enfoques políticos, estudios e investigaciones con efectos sociales, etc.) esto da cuenta de una clara, digna y saludable orientación - no neutral- que estropea la objetividad "neutral de la ciencia tradicional".

Los estudios y las prácticas son rigurosamente realizadas -profesionales antropólogos- con convicciones políticas, la utilidad práctica de esos depende del sujeto político que lo asuma. Un aspecto a entender y estudiar más es el tipo de relación entre la Antropología como ciencia y como práctica en relación con los sectores políticos organizados (partidos o movimientos), ¿cuánto afectó la militancia o convicciones humanas y políticas de estos profesionales? Es evidente que después de estas cuatro décadas, la Antropología no está, ni debe estar en la academia solamente. En el Ecuador el quehacer antropológico se ha ido construyendo más allá de las aulas. La vivencia cotidiana, el relacionamiento y la cercanía del profesional antropólogo con el entorno y los sujetos en él, hace que esta ciencia esté viva. ¿Pero cuál es el lugar de la Antropología? Se puede afirmar que hay varios lugares de y para esta ciencia social, que se verifican por sus límites, que se expresan en sus propias geografías teóricas y en el sujeto con el cual interactúa. Sin embargo uno de reciente surgimiento, se convierte en un lugar demasiado complejo. El Estado, en la actual coyuntura, se vuelve otro lugar para la Antropología con todas las implicaciones que esta afirmación tiene.

Hay una prolífica y vasta publicación en temas antropológicos (etnografías, diagnósticos, análisis, etc.), sin embargo en términos de teoría, hay pocas cosas nuevas. Del total de investigaciones de pregrado, en estos cuarenta años, no se han hecho estudios teóricos. Sólo en el 2013, se hace la primera investigación de carácter puramente teórico (Antropología Filosófica), por lo demás todas los trabajos son aplicaciones y estudios de caso muy impor- 
tantes, eso da cuenta de una debilidad de la academia para transmitir mecanismos para crear pensamientos propios "pese a que se puede encontrar valiosos y nuevos aportes temáticos, podemos decir que existe una asimilación poco crítica de enfoques foráneos, sin generar instrumentos teórico metodológicos propios para entender la realidad ecuatoriana" (Andrade, 2011, p. 58). Andrade sostiene que la UPS, lleva la delantera de los debates y cuestionamientos a la Antropología tradicional, pues incorpora nuevas nociones como la Antropología insurgente, la descolonización de la mirada, etc. Esto es resultado de un acto que se concreta en la realidad y que luego la academia la recoge y conceptualiza como antropología insurgente, la creación del concepto sirve para nombrar un hecho de la realidad, pero además se vuelve en razón desde donde se crea un camino y una orientación. Cuando se nombra algo, se le da nombre, es cuando tiene identidad y existe... ese momento lo hizo la Universidad Salesiana, ahora ese enfoque se lo enriquece con la práctica profesional.

Los antropólogos y antropólogas desarrollaron esta ciencia desde una perspectiva de compromiso, de involucramiento en y con el "objeto" con el que se relacionan o interactúan, ello sin perder la condición de externo. Esta característica le da un valor distinto al trabajo y narración etnográfica. En ese primer momento "los estudiantes actuaban como "compañeros" de las organizaciones indígenas, campesinas, negras o los obreros. La escuela de Antropología -PUCE- mantuvo acuerdos con las organizaciones indígenas y trabajadores por más de una década. El aporte de la Antropología fue redefinir las categorías marxistas y complementar el análisis con los conceptos de grupos étnicos, pueblos y nacionalidades" (Andrade, 2011, p. 40). Así el trabajo del etnógrafo es un instrumento que viabiliza las demandas, posiciona temas, plantea contenidos y preocupaciones del sujeto con el que se trabaja. En el Ecuador se trabaja con sujetos que tienen saberes, propuestas y sobre todo poder radicado en lo colectivo. El cientista social en este caso no es el intermediario o el ventrílocuo entre las necesidades del sujeto y la sociedad. Los sujetos tienen voz propia. Directa o indirectamente, con intensidad o débilmente, con compromiso o solo "laburo", el trabajo realizado por estos profesionales ha estado, cruzado por apuestas de vida. Ahí la Antropología se vuelve potenciadora y cobra mayor sentido porque no se encuentra solamente en la academia. El compromiso como eje articulador o la visión desde el gabinete para la comprensión de la realidad social, son las posturas asumidas por las dos universidades de pregrado, que las hacen diferentes. 
Un aspecto que destaca a la práctica antropológica ecuatoriana es la línea editorial y en eso la creación de la Editorial Abya-Yala destaca en todo el continente. Es bastante conocida en América en el campo antropológico y sobresale con innumerables reconocimientos, esto según uno de sus fundadores "es porque hemos buscado los contactos, hemos ido a congresos, a ferias de libros. Es una propuesta única en su género" (Bottasso, 1997). A pesar de la importante dimensión de la producción de estudios antropológicos como la última publicación de Patricio Guerrero sobre El trabajo antropológico, hay pocas referencias ecuatorianas a teorizaciones sobre la misma. En este sentido, destaca Bolívar Echeverría que desde la Filosofía aporta conceptualizaciones sobre la cultura; y el mismo Patricio Guerrero desde la visión andina enfrenta la ruptura occidental de separar la razón y el sentir con un enfoque integral. Es muy lamentable que a pesar de la importancia de los aportes, estos no sean valorados en su real dimensión, las academias aun aprecian literaturas foráneas más que las propias.

En cuanto a eventos de importancia destacamos el XVIII Foro de Estudiantes Latinoamericanos de Antropología y Arqueología -FELAA- sobre Cultura y Naturaleza en América Latina: escenarios para un modelo de desarrollo no civilizatorio, realizado en Quito entre el 17 y 23 de julio de 2011, cuya iniciativa y gestión fue de los estudiantes de Antropología de la Universidad Politécnica Salesiana conjuntamente con sus pares de Antropología y Arqueología de la Pontificia Universidad Católica de Quito. Este encuentro académico al que asistieron representantes estudiantiles y ponentes de varios países de la región fue publicado por Abya-Yala a mediados de 2012.

La información revisada da cuenta de un proceso vivido por la Antropología consistente en tres etapas, la primera que es el surgimiento de esta ciencia social y su vinculación con los contextos de los años setenta en que había una demanda fuerte de lucha por la tierra y una emergencia identitaria nacional. Un segundo momento, es la consolidación de los procesos sociales indígenas y los diversos aportes que realizó la Antropología en términos de dar a conocer al "otro" ante la sociedad nacional. Y finalmente hay un fuerte impulso de medidas de ajuste estructural que generan una diáspora de ecuatorianos y una crisis generalizada. En ese contexto, la Antropología se convierte en un importante sector dedicado a acciones de desarrollo, investigación aplicada y generadora de propuestas de acción. Sin embargo encontramos que hay otro momento más, que es el paso de esta última etapa en la que los antropólogos eran agentes de desarrollo (trabajando en ONG, organismos in- 
ternacionales y relación con las organizaciones sociales), a la etapa que vivimos ahora a partir de la promulgación de la Constitución del 2008. Desde entonces esta ciencia social ya no es la misma, ni el ejercicio profesional son los mismos. La característica fundamental de esta nueva etapa se sustenta en que ahora hay un nuevo sujeto de estudio, el Estado en su conjunto.

La actual Constitución ofrece un vasto campo para el ejercicio profesional al incluir como eje central de la política del desarrollo la interculturalidad, la plurinacionalidad y el patrimonio. Por primera vez estos temas son preocupaciones medulares. Este debe ser un desafío para la academia en cuanto a cubrir esa demanda. Actualmente nos encontramos en la disyuntiva de un Estado que demanda la fuerza de trabajo del profesional antropólogo, las temáticas sobre las que se forma el profesional no caminan en la misma ruta que las demandas. A lo largo de estos cuarenta años, hemos tenido tres constituciones, hay registros y testimonios (Fernando García, Moreno Yánez, Pacari, Larrea) de la participación de antropólogos en todas ellas. Se ha contribuido en términos constitucionales a través de temas referidos a plurinacionalidad, desarrollo, inclusión, cultura, historia, identidad, etc. Es la última Constitución la que marca la diferencia. Veamos que dicen algunos de sus propulsores.

Según Ana María Larrea (2011) el trabajar en la Secretaría Nacional de Planificación y Desarrollo (SENPLADES), permite incluir las preocupaciones antropológicas sobre cultura, etnia, derechos, sociales, etc., no a manera de discurso, sino también en el diseño de herramientas de aplicación en lo cotidiano, cosa que antes no se daba. Con esto según ella, se vuelve a la Antropología en una de las principales herramientas para el cambio social, además porque se cumple varias etapas del proceso antropológico que son la investigación para generar sustentos y argumentos, diseño de propuestas de desarrollo y el diseño de herramientas y políticas para llevarlas a cabo.

Daniela Fuentes, Subsecretaria del Ministerio de Cultura, tiene una visión más autocrítica respecto al rol de la Antropología y la forma cómo se aplica en el Estado:

El tema de la investigación es un tema que le corresponde a la academia, yo no creo que nosotros como instituciones públicas debamos hacer investigación, porque yo creo que la institución pública queramos o no, siempre tiene el color de algún partido político y entonces si tú haces investigación, esos datos van a tener el color del partido político. La investigación tiene que estar en la academia y esa academia además, tiene que crear profesionales que 
sirvan a las necesidades del país. Y hay un divorcio tal que el Estado necesita contratar millones de dólares en consultorías que bien las universidades podrían hacer en todos los ámbitos (Entrevista 2014).

Alexis Rivas, Exministro Coordinador de Patrimonio, Viceministro de Coordinación Política del actual gobierno y miembro de la Comisión de Política Económica, Social y Ambiental de la UICN -Unión Internacional para la Conservación de la Naturaleza-, plantea que la antropología es una disciplina que facilita espacios teóricos y prácticos. Este enfoque lo lleva a sostener que "no existe contradicción entre seres humanos y naturaleza" (UICN-09.05.2011), por cuanto una Política de Estado sustentada en derechos permite una participación adecuada para beneficio de todos. Para este antropólogo, la conservación y los pueblos indígenas son parte del mismo tema porque "el factor humano es crucial para la conservación" (2011).

Aquí cabe una pregunta ¿Es esa forma de acción la manera cómo la Antropología debe vincularse con el Estado, en aras de ser una ciencia social de profesionales comprometidos con el cambio? ¿Cuál debe ser la manera de vinculación? Mirar a esta ciencia social como una herramienta solamente es quitarla su valor crítico, transformador. Herramienta que produce y reproduce los resultados de quien la maneja. De ninguna manera debe ser esa la relación de la Antropología y su presencia en el Estado; es la concreción de muchos aspectos en el Plan Nacional del Buen Vivir con criterios de interculturalidad, etnia, género o generación. Al parecer ahí se logra la inclusión anhelada por esta ciencia social y los profesionales que lo apoyaron y lo entienden como una victoria. La comunidad antropológica-que no trabaja en el Estado- más bien lo mira con recelo. Algo que genera confusión en los intelectuales es que no hay claridad sobre el sujeto de los cambios. El Estado no es, ni debe ser el sujeto de los cambios, los profesionales ahí son solo funcionarios que viabilizan esos cambios y nada más, el protagonista es el pueblo.

\section{La carrera de Antropología Aplicada de la Universidad Politécnica Salesiana vista desde adentro}

El P. Juan Bottasso, fundador de esta carrera en la UPS, indica que debieron pasar varias circunstancias antes de contar con la carrera que según él son las siguientes: Conseguir un aval académico, generar la demanda, diseñar la modalidad a distancia. Estaba claro que esta carrera, para el P. Bottas- 
so, no se orientaba a "producir investigadores" sino a generar herramientas para que los profesionales y en el primer momento los misioneros o catequistas hicieran mejor su trabajo. Por ello los contenidos trataban "descubrir, qué procesos, qué condicionamientos, qué presiones tuvo la gente del lugar para que viva como lo hace". Todo esto propone una rigurosidad académica que se entendía de la siguiente manera:

Mi propósito no es establecer filtros, sino atractivos y motivaciones. Si se ponen exigencias, al final quedan afuera los que en verdad lo necesitan y dentro quedan unos muchachos de ciudad que puedan hacer bien sus exámenes, pero siguen en la ciudad y no cambian nada. Quiero privilegiar la etnografía, porque no se trata de sacar teorías sino de reunir información, abrir los ojos sobre las situaciones, que por verse a diario no llaman la atención (Bottasso, 1997).

Cuando desde la UPS se plantea que para el desarrollo de una Antropología distinta, comprometida, vivencial, hay que razonar con el corazón, se plantea un quiebre epistémico profundo, que han hecho de las aulas un fin y no el medio y del Estado el principio y el fin de sus objetivos. El desarrollo de la Antropología en el Ecuador tiene su horizonte en una cercanía con el entorno social, con los sujetos concretos, con un compromiso y no solo con la "objetividad científica" o la utilidad en el Estado. Esta ruptura epistemológica se inscribe en el proceso de adopción de pensamientos propios, en esto coinciden desde distintas vertientes Bartoli (2001), Colajanni (2000) y Cucurella (2001) cuando hacen un recuento de la Antropología aplicada en el Ecuador y desde la trascendencia Salesiana en el país. Entre estas rupturas señalamos los planteamientos que según Luis Herrera (2011) son principios que han mejorado la carrera: La Antropología como formación y currículum (que implicó niveles de rigurosidad académicos). La Antropología y los procesos de investigación, es decir que la investigación acompañe procesos que viven los estudiantes en sus propias realidades y finalmente la Antropología y los procesos de profesionalización. Según él, la Antropología en la UPS, toma partido, no es neutral porque no fomenta verdades universales.

Esto tiene relación directa con el planteamiento de Patricio Guerrero (2011) que promueve crear una Antropología que combine la razón y los afectos, con ello se conseguirá una sociedad más humana, y profesionales comprometidos. Es evidente entonces que de los planteamientos originales que motivaron la creación de esta carrera, se ha pasado a una rigurosidad 
académica que no descuida la vinculación de los sectores a los que se orientó la carrera en un principio. Lo llamativo de esta carrera es una frecuente combinación y tensión entre rigurosidad académica y apertura a la participación de sectores tradicionalmente excluidos.

Durante los veinte años de la carrera de Antropología de la UPS hay 176 graduados, 101 mujeres, 75 hombres. El mayor número de graduados son mujeres por el enfoque de la carrera y la orientación al público adulto que tiene pocas condiciones de tiempo para estudiar con modalidad presencial. Entonces la UPS ofrece ventajas comparativas que otras ofertas no la tienen. Estas ventajas son bien acogidas por mujeres que buscan culminar sus estudios o que por razones personales y de familia deben asumir un doble rol y no podrían estudiar de manera presencial. Haciendo una radiografía de los estudiantes de Antropología de la UPS podemos decir que hay muchos profesionales de diversas carreras (economistas, comunicadores, tecnólogos, etc.) que buscan herramientas para comprender mejor el espacio donde desarrollan su profesión por eso se encuentran cursando otra vez la universidad. Las edades de los participantes son un indicador muy importante, pues la mayoría son adultos con familia y con mayor o menor experiencia en temas sociales. Hay aquellos que han salido de la Universidad Católica y que dadas las facilidades que provee la modalidad a distancia "se cambian a la Salesiana" para culminar sus estudios de pregrado.

Al aplicar la encuesta se consultó cuántos de los estudiantes de los tres últimos niveles tienen una profesión previa y se encuentran laborando, la mayoría de hombres tienen profesión anterior y se encuentran trabajando a diferencia de las mujeres que en porcentaje menor no tienen profesión previa, pero sí se encuentran trabajando durante la carrera. Asumiendo que la mayoría son personas adultas, la pregunta que se planteó buscaba entender las motivaciones para estudiar Antropología en la UPS. La respuesta más interesante proviene del lado de las mujeres que plantean que estudian esta carrera por compromiso social. La segunda respuesta plantea las razones personales como motivación. Las opciones de respuesta referidas a salario, prestigio o por mejorar relaciones sociales, no son representativas.

Asumiendo que la mayoría de estudiantes de esta carrera tenían profesiones o estudios previos se consultó el "Beneficio que obtuvo de la Carrera de Antropología Aplicada". Las respuestas son variadas pero muestran que a las mujeres les sirvió para mejorar los niveles de análisis y mejorar la investigación e interpretación. Para los hombres las respuestas son variadas pero 
coinciden con las mujeres en cuanto a la interpretación e investigación. En consecuencia con lo anterior se indagó para conocer qué ha obtenido de esta carrera. En un sentido material ¿qué ganó estudiando esto? Tanto hombres como mujeres reconocen que lo que obtuvieron, producto de sus estudios, en esta carrera es principalmente conocimiento. Las otras opciones ascenso social, solvencia discursiva o económica, mejor salario o prestigio no muestran interés o no son resultados vividos por los estudiantes que ya trabajan. En resumen, el ingreso a estudiar esta carrera no está medido por la búsqueda de prestigio social, mejorar niveles económicos o prestigio, que es la razón por las que muchos asumen una carrera. Es decir que los motivantes no son obtener un título para lograr un proyecto de vida acorde a la lógica y las demandas del mercado capitalista de trabajo.

\section{Gráfico 1}

\section{Beneficio que obtuvo de la Carrera de Antropología Aplicada}

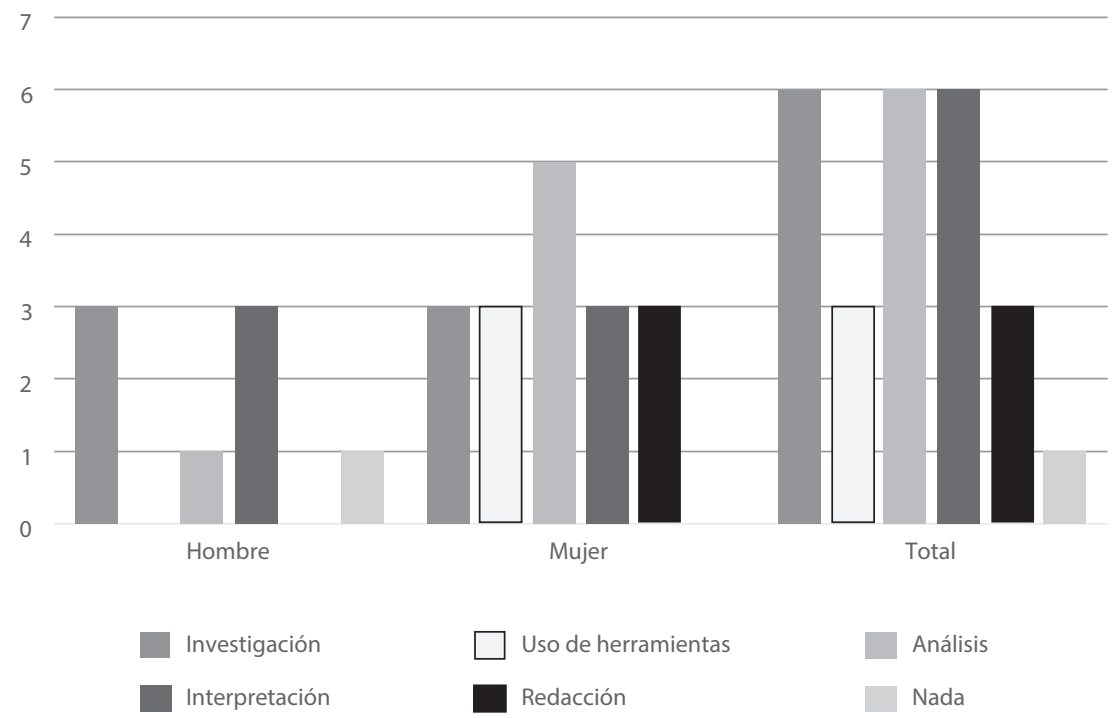

Fuente: Encuestas de investigación Elaboración: Hernán Hermosa 


\section{El desarrollo de la Antropología a partir de los trabajos de grado}

\section{Temas de trabajo de grado}

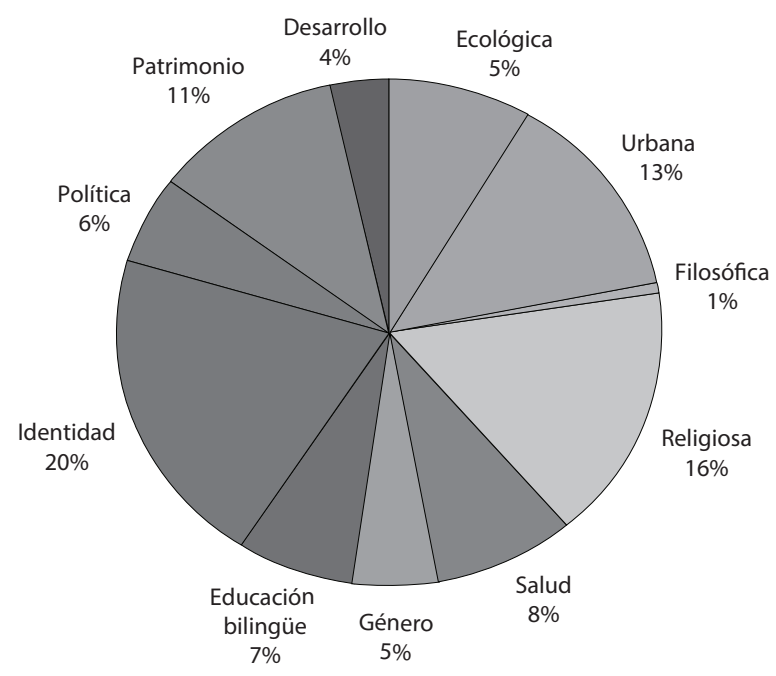

Fuente: Encuestas de investigación

Elaboración: Hernán Hermosa

En esta parte del documento se hace un análisis de los trabajos de grado, a lo largo de estos años de carrera, donde encontramos que hay 142 investigaciones realizadas. Los temas que más convocan la preocupación de los futuros antropólogos son identidad (29), Antropología religiosa o simbólica (23), Antropología urbana (19) y patrimonio (16). Entre el 2000 y 2004 es cuando más graduados hay, en cinco años se gradúan casi el $40 \%$ de todos los graduados de la carrera en esta universidad. Tanto hombres o mujeres investigan en diversos temas y reflexionan en torno a ello. Es importante recordar que a lo largo de la carrera hay más mujeres graduadas que hombres. Entre los temas identificados hay uno en particular que es el ubicado en la categoría patrimonio que llamó la atención en este estudio porque se refieren a museos o arqueología. Este último en particular es uno que no se imparte 
en la Universidad Salesiana. Este número de trabajos se debe a que muchos estudiantes de la Universidad Católica o profesionales vinculados a estos temas obtuvieron su título en la Salesiana.

Según las investigaciones, a partir del año 2000, la Antropología urbana empieza a ser preocupación de los antropólogos que se gradúan con trabajos referidos a este tema, anteriormente no se registra ninguna investigación. Un gran número de investigaciones sobre este tema se registran en un corto tiempo. Hay por tanto un vuelco respecto a las preocupaciones anteriores de carácter más campesino o de identidad, pero no una mirada a lo urbano. Sorprende el alto número de antropólogos vinculados al Estado como funcionarios, muchos cumpliendo -como en la mayoría del Estado- roles políticos y no técnicos. La sorpresa se justifica pues el número de trabajos sobre este tema es mínimo. La Antropología política no es un tema de mayor preocupación.

Es interesante que en momentos en que el país vivía la efervescencia del movimiento indígena y social, y toda la lucha antineoliberal, a finales de los noventa e inicios del dos mil, el número de investigaciones no hace referencia, sino de manera minoritaria al movimiento social en cuestión. Los trabajos de investigación en ese entonces hacen referencia a la identidad desde la visión de los migrantes y las preocupaciones de familias divididas y sociedades incompletas como consecuencia de ello. Este aspecto llama la atención, pues la Universidad Salesiana como institución tenía compromiso con el movimiento social. Es decir que los estudiantes de Antropología de aquel entonces tenían preocupaciones de índole distinta a la que vivía la universidad. No necesariamente hay un empate conceptual entre el enfoque de la universidad y la carrera, y las preocupaciones de los estudiantes al hacer sus trabajos de grado.

\section{Aportes de la Carrera al campo profesional}

Para completar la información de este tema, a continuación seleccionamos algunos testimonios producto de las entrevistas realizadas a los antropólogos. Se busca entender desde la perspectiva profesional cómo aporta a su trabajo la formación que recibió, los testimonios de los entrevistados son los siguientes.

La Antropología es una ciencia que permite a un religioso como yo, no estancarse en su preparación, que le permite incursionar en otros ámbitos y 
de manera muy especial en las herramientas que propone, en ese caso para leer la cultura, para tener herramientas para comprenderla y a la vez hacerse comprender, ahí es un encuentro que pueda traducir un producto que pueda enriquecer a todos (P. Antonio D’Agostino).

Creo que el convertirse en antropólogos de la Universidad Politécnica Salesiana, tiene a favor dos elementos de gran importancia: por un lado hemos sido educados con una orientación crítica y por otra parte, hemos desarrollado sensibilidad y compromiso con los menos favorecidos. Estos dos elementos son básicos y aportan a la construcción de "honrados ciudadanos" que es una de las premisas de la educación salesiana. Además nos potencian en nuestro quehacer profesional, puesto que al entendernos como sujetos integrales, buscamos que nuestra actividad diaria en los sitios de trabajo, esté transversalizada por valores y una alta calidad académica que estamos mejorando día a día para poder ser más y servir mejor (Daniela Ochoa, docente, Antropología Aplicada, Universidad Salesiana).

Estudié Antropología porque sentía que tenía que entender más la energía del mundo del otro al que amaba, obtuve herramientas para entender la cosmovisión y todo lo que comunica a nuestros mundos. Yo pertenezco a los dos mundos. La Antropología le da la sabiduría para a más de entender al otro, que lo puedes manipular. Puedes tu manipular a los grupos por obtener dinero, sacar proyectos y si no hay una formación en tu conciencia entonces el dinero y el poder de controlar al otro termina corrompiendo al antropólogo y a la antropología. Entonces cuando se utiliza el conocimiento, el saber, el poder, para manipular a los otros eso se hace un mercado de corrupción. La Antropología me ayudó a entender todas estas cosas y poder caminar por el lado del bien, sanando a la gente, porque yo soy sanadora (Nelly Guevara, sanadora).

Alguna vez me dijo alguien, tú para hacer lo que estás haciendo tienes que ser $\mathrm{PhD}$, porque esos son los que hacen la teoría, así me dijeron. Les dije vean discúlpenme pero, mi abuelo, mi papá son los $\mathrm{PhD}$. En la Universidad nos enseñan a estar leyendo, pero ya desde la parte más crítica, más vivencial, más en el terreno, hay que comenzar a teorizar. Mucho problema tenía yo para escribir los ensayos, acá en mi casa, es que mira José tienes que tu escribir en tercera persona "casi desde allá lejos". Pero eso desde lejos eso es un atar de manos. Para decir que soy objetivo y científico, yo casi siempre peleo contra la ciencia y no soy casi nada objetivo, soy bien comprometido y hablo desde dentro, entonces yo creo que nosotros la afroecuatorianidad estamos asistiendo a escribir desde dentro o pensamos desde dentro o como diría Juan García Salazar, casa adentro. Entonces si eso no es academia no es ciencia me importa menos (José Chalá, afrochoteño. Consultor y funcionario público). 


\begin{abstract}
Si hay un distintivo de la Antropología latinoamericana es esta exigencia que tenemos los académicos de no poder hacer ciencia separados de los problemas que vive la gente aquí, por la realidad que vivimos, es muy difícil que sea un antropólogo estrictamente académico, eso no se sostiene. Eso nos lleva a algunas formas de compromiso de diferente tipo, reconozco que la Antropología, en el caso ecuatoriano, ha aportado un montón de cosas en el levantamiento del país como nación o estado, la misma discusión de la plurinacionalidad, los no contactados, la identidad. Esos temas están claros en el enfoque de la Salesiana (Fernando García, profesor FLACSO).

La Antropología que me gustó realmente es la posibilidad de, desde la experiencia profundizar las propuestas teóricas y no al revés desde las teorías ir a buscar a ver si es que en algún lado la realidad se asemeja a esto. Me acuerdo que tuve compañeros de la Católica que se pasaron acá (Moisés Arcos, director de escuela Nina Pacha con pedagogía Waldorf).
\end{abstract}

Según los entrevistados, es en el espacio público donde actualmente se aprecia la profundidad del enfoque de la UPS respecto al acercamiento a la realidad y el compromiso social. Hasta hace un par de años esta realidad estaba mediada por el predominio de un sujeto social que era "el otro" (el indio, el negro, la mujer, el gay) en contacto directo con el Estado nación y la sociedad de manera conflictiva. El profesional antropólogo, en ese entonces, era un mediador o incluso ventrílocuo y acompañante de procesos protagónicos del país. Actualmente ese contacto se da a través de la mediación y la directriz del Estado, esto por mandato constituyente. En ese caso el antropólogo cumple un rol ejecutor-operario. Lo cual otorga a la Antropología un rol funcional y despojado de protagonismo, en la medida que es una profesión regulada y controlada se vuelve funcional y tutelada. Es decir que el sujeto de la Antropología, ahora también es el Estado articulador de relaciones sociales, de políticas públicas, de creación de sentidos, de generación de discursos.

Pero el enfoque de acercamiento a la realidad, el construir una Antropología vivencial del "corazonar" no deja de tener pertinencia, más bien en este contexto, se vuelve urgente y necesario, pues la Antropología Aplicada debe continuar junto a los sujetos subalternos en este acercamiento del Estado. Si esto es así se requiere entre otros aspectos enriquecer los enfoques de la UPS expresados en los contenidos de materias que actualmente se dictan en la carrera, o agregar y enriquecer los que ya existen, con algunos de los siguientes elementos. Los entrevistados coinciden ver en el Estado, al nuevo 
sujeto de estudio de la Antropología, que no excluye la cultura y la comprensión del otro, sino que se vuelve al Estado, en otro "objeto de las preocupaciones de esta ciencia social", un objeto necesario de entender y caracterizar. Pero anexan este nuevo aspecto que tiene que ver precisamente con el desarrollo del contexto en que vive el país.

\section{La Antropología como práctica profesional en Ecuador}

Se entrevistó a catorce profesionales, hombres y mujeres, seleccionados de acuerdo a la especialidad en la que se desarrollan (artistas, académicos, miembros de pueblos y nacionalidades, funcionarios públicos y personas vinculadas al sector privado). A todos, independientemente del área de trabajo o especialidad, se les preguntó lo mismo. A lo largo de estos cuarenta años de Antropología en el Ecuador, es evidente que hay muchos campos de conocimiento en los que los profesionales antropólogos se especializan. Se puede afirmar que casi no hay área laboral en la que no haya un antropólogo. Precisamente por ello, se puede afirmar también que la Antropología en el Ecuador está fuera del espacio académico. De las entrevistas se encuentra que la academia es poco permeable y por ello los avances que se han logrado no se los puede acumular o reconocer de tal forma que contribuyan a desarrollar mejor esta ciencia social en el Ecuador.

Cuando una persona camina por la calle y observa un edificio, un puente o ve un hospital y médicos o escucha una interpretación, sabe que ahí hay un profesional, lo sobreentiende o lo percibe; pero ¿cómo se percibe la obra o acción práctica de un antropólogo? De las entrevistas se deduce que los profesionales antropólogos y antropólogas han aplicado diversas herramientas no exclusivas de esta ciencia social, así como se han diseñado muchas más para ejercer su labor. Se puede afirmar por tanto que, por falta de mecanismos de aplicación de nuestros conocimientos, se ha acudido a la creatividad para el desarrollo de la profesión. Esto se demuestra en la investigación, la docencia, la aplicación al desarrollo, etc. Los profesionales en su mayoría reconocen que durante su formación sintieron que eran orientados a la investigación y la docencia como principal objetivo de formación y por ello al momento de desarrollar otro tipo de acciones se encuentran con obstáculos que deben superar sin mayores acumulados. Pero no todos quieren ser 
investigadores o académicos. Ahí, entonces, faltan áreas de especialización en la formación.

\section{Sobre el trabajo profesional}

Amparo Eguiguren (2011), pregunta “¿la práctica antropológica produce una gran cantidad de conocimientos, pero quién controla ese conocimiento?" Como consecuencia de este cuestionamiento ampliamos la pregunta con otros elementos: ¿dónde está toda esa amplia gama de conocimientos desarrollados a través de estudios, informes de trabajo o gestión, investigaciones o consultoría? Esos son aportes al país que no pueden estar desperdiciados o beneficiando a determinados intereses. La mayoría de entrevistados hacen referencia al ejercicio profesional en los actuales momentos. Todos reconocen que ahora ser profesional está más complicado pues no hay regulaciones que defiendan el ejercicio antropológico, esto está agravado por la falta de seguridad social, estabilidad laboral, reconocimiento profesional, etc. Todo esto conspira para tener un ejercicio digno de la profesión que en muchos casos se vuelve inestable y por ello informal. El antropólogo se vuelve un profesional informal.

También se discute respecto a lo que hacemos como profesionales y la validez de ello, pues finalmente se funcionaliza o se minusvalora. No estamos haciendo investigaciones científicas de larga duración, de periodos de tiempo o procesos como debiera ser en ciencias sociales. Ante ello cabe una pregunta ¿son las consultorías una forma de investigación válida? ¿Cuánto conocimiento práctico provee este instrumento de información? ¿Cuál es su validez científica? De acuerdo a la ley de consultoría, ¿el trabajo en ciencias sociales puede ser calificado o valorado de la misma manera que aquel que realizan otros profesionales como médicos o ingenieros?

\section{Sobre el Estado}

Se reconoce que el trabajo en este nuevo campo laboral, siempre establece relaciones de poder y por ello de desigualdad, es por tanto un espacio político que se lo debe entender para saber cómo desarrollar la profesión desde una perspectiva ética en él. Es necesario caracterizar ese poder, visualizarlo y ubicarlo. Pero a la vez se reconoce que es necesario estar ahí para cambiarlo y desarrollar otras formas de relacionamiento. El del Estado no es una relación de poder sutil, como lo era el acercamiento de profesionales no 
vinculados al Estado hacia las comunidades o el otro. El Estado se acerca de forma directa y sin mediación. El Poder en este caso se impone. Así quienes han tenido sentimientos de adhesión a causas reivindicativas, ven el ejercicio de poder como algo que no pueden manejar ni comprender.

Pero cualquier poder genera un contra poder y eso es lo que se nota de la experiencia de los mismos antropólogos vinculados al Estado. Se reconoce que el Estado genera muchas resistencias y por ello creen que su accionar como profesionales dentro de este espacio laboral es momentáneo. Algunos antropólogos en conversaciones informales, asumen que se debe profundizar una línea dura, es decir ejercer el poder para que "todo esto se ordene, sino cada cual quiere imponer su razón" el Estado y ellos como parte de él, les da la potestad de ser tutelares de ese orden. Para Ana María Larrea (2011) Subsecretaria de SENPLADES, la Antropología en el Estado ha contribuido a ampliar la democracia, por su accionar interdisciplinar y sobre todo a tener una perspectiva integral del Estado en su accionar. Es por tanto, para ella, una herramienta valiosa en el ejercicio de poder.

¿Qué hace un antropólogo o antropóloga? Esta fue una pregunta complicada de responder para todos los profesionales experimentados a quienes se consultó. Profesionales como médicos, está claro, que poseen conocimientos para curar algún mal. Los ingenieros construyen o hacen caminos, los abogados igual tienen su especialidad claramente. Sin embargo, la Antropología al tener una posibilidad interdisciplinar no tiene un sólo aspecto de manera única. Los entrevistados señalan que algunas de las especificidades de esta profesión es pensar, pero de manera crítica y el hacerlo de esa manera lleva a que los resultados o productos generados posibiliten entender una "realidad" desde diversos puntos; se muestran "otras verdades". Otros dicen que sirve para diseñar planes y proyectos o para acompañar procesos. Otros más bien sostienen que la investigación es la característica fundamental, pero a la vez reflexionan que los aspectos anteriores también lo hacen profesionales como sociólogos, economistas o filósofos. En conclusión, la Antropología para los profesionales entrevistados, no tiene una posibilidad única y ahí radica su riqueza. El producto, resultado de las acciones de los profesionales de esta carrera se encuentran en las artes, la cultura, la gestión social, la identidad o plurinacionalidad en forma de estudios, análisis, publicaciones, acciones de carácter público, entre otras. 


\section{Temas de debate para la Antropología. A manera de conclusiones}

El marco normativo en el Ecuador y en la región, requiere ser pensado en función de los intereses del Estado, de los pueblos y nacionalidades, de la ciudadanía con sus complejas diversidades, las transnacionales y los proyectos extractivos. Es desde estas normativas políticas y su aplicación, desde donde se debe entender el Estado actual y el rol de la Antropología. El Estado diverso, contradictorio y complejo. La realidad del Estado en la actualidad, frente a una constitución "garantista", expresa una tensión entre intereses económicos y los derechos a amparar. Es por tanto un Estado en paradoja. Es decir, es el mismo que reconoce y plantea la defensa de los derechos como el Convenio $169^{4}$, que acoge y plantea el modelo neoliberal como propuesta de desarrollo, promueve la interculturalidad, pero criminaliza los derechos a la protesta.

El Estado trata de manejar varios procesos contradictorios al mismo tiempo. Esto pone a la Antropología frente a temas en los que trabaja, pero que a la hora de aplicar, el Estado tiene una propia visión al respecto. La información, por más adecuada o sistematizada que sea, no es acogida por el Estado. La Antropología trabaja con la complejidad porque tenemos un espíritu crítico, que se sustenta desde su ser y desde la elección del sujeto de estudio, la cultura. Todo esto se contrapone a la lógica del Estado que simplifica, homogeniza y con todo esto hegemoniza. Por ello tiene dificultades en plantear políticas diferenciadas. Cuando esto se aplica con profesionales antropólogos al mando, es que la visión de la cultura y la complejización que es la herramienta propia del antropólogo, se burocratiza. Es decir que el Estado obvia responder preguntas incómodas. Tenemos datos que son relevantes y que sirven para tomas decisiones, pero son incómodos; no hay mecanismos de orientar esa incomodidad. El Estado busca profesionales antropólogos dúctiles.

Los antropólogos en América Latina, no separan la academia y la relación con la política, la ecología, la participación en procesos. Uno de los roles de la Antropología en la actualidad tiene que ver con que, el antropólogo o antropóloga, deben pensar en la autonomía de los sujetos pero, no ser

4 Convenio 169 sobre pueblos indígenas y tribales en países independientes. $76^{\circ}$. Conferencia de la OIT, Ginebra, 1989. 
neutral. Esto lleva también a una modificación en la forma de redacción del discurso. Lo más útil en Antropología no es responder preguntas, sino formularlas. Las preguntas conducen a indagar a buscar. Es decir, si nos preguntamos sobre el otro, podemos preguntarnos por nosotros mismos. Hacer preguntas es reflexionar, y en eso esta ciencia contribuye de gran manera.

Es decir la historia de la Antropología es también la historia de la deculturación de esta ciencia social. Muestra de ello y como producto de todo este proceso es que los que iniciaron siendo objetos de estudio, son ahora sujetos de su propia realidad, tienen su propia voz, es decir el antropólogo ha dejado de ser el ventrílocuo. Sin embargo de esta verdad, el Estado ahora se convierte en el ventrílocuo de ellos. Pero este no se nutrió de todos los debates que fortalecieron a la Antropología, sino que muestra su rol de control a ciudadanos que como los demás tienen derecho a voz propia. Esto continuó por todas las décadas en los que esta ciencia se consolida en el Ecuador, el antropólogo consciente y solidario que trabaja para la consecución de un mundo distinto y por ello comprometido con las causas de los sujetos a los que estudia y acompaña. A ratos ese nivel altruista subsiste en el rol de los antropólogos que trabajan para la función pública en el Ecuador. Hacer lo mejor, pues si no lo hago yo que tengo consciencia, alguien lo hará de manera inconsciente. Es también sentirse indispensable.

Los problemas éticos no están solo con la relación con empresas o Estado. La responsabilidad está en proponer procesos de reflexión a la sociedad. Por ejemplo la Antropología ha dicho en épocas pasadas, que la Amazonía es un escenario de lucha anticapitalista, pero esto no es la visión de las organizaciones. Eso que ha dicho no es verdad, pero ha impedido que se vea la realidad de manera clara. Esto también ha hecho que el Estado asuma ciertos conceptos planteados por la Antropología como ciertos, incluso convirtiéndolos en política pública. Eso nos lleva a una realidad, hay un gusto por los conceptos o enfoques, hay esa necesidad de generalizar discursos con el mismo sentido de la ciencia occidental.

En los países de América, cada vez la Antropología va teniendo un rol de servicio de las empresas multinacionales o del Estado. Esto porque las legislaciones plantean que no se puede hacer ninguna actividad productiva, si antes no se hace una prospección arqueológica o cultural. De ahí que el profesional cumple actividades a pedido, como un requisito. La ciencia social se vuelve un requisito y no un aspecto determinante. Esto no permite desarrollar actividades de investigación con carácter científico o rigurosos 
procesos de análisis. Sobre esto, países como Perú, tienen mayores avances en esa orientación de la ciencia antropológica y también han desarrollado herramientas que se expresan en los mismos contenidos que las academias desarrollan con los alumnos.

En este sentido, la Carrera de Antropología Aplicada de la Universidad Politécnica Salesiana, a mediados de 2011, tomó la iniciativa de propiciar el XVIII Foro de Estudiantes Latinoamericanos de Antropología y Arqueología (FELAA), para que fueran ellos quienes articulen sus propuestas como insumos a la academia. De manera que, "la antropología, cada vez más, se sacude del encargo (...de la carga) que le atribuye la misión de construir clasificaciones sociales, sobrevisibilizar las diferencias para, en última instancia, sobredeterminarlas política y económicamente" (Juncosa, 2012, p. 188).

\section{Bibliografía}

Alfaro, E., Enríquez, K., y Flores, Y. (2012). Naturaleza y cultura en América Latina. Escenarios para un modelo de desarrollo no civilizatorio. Memorias del XVIII Foro de estudiantes latinoamericanos de antropología y arqueología-FELAA-. Quito, Universidad Politécnica Salesiana, 17-23 julio 2011.

Andrade, S. (2011). Informe del proyecto La conformación y el desarrollo de la Antropología como disciplina en el Ecuador. Quito: PUCE.

Bartoli, L. (2002). Antropología Aplicada: historia y perspectivas desde América Latina. Quito: Abya-Yala.

Bottasso, J. (1997). Entrevista. En: Memorias de Talleres de Antropología Aplicada. Quito: UPS.

Colajanni, A. (2000). Antropología Académica y Antropología Aplicada en este milenio. En: Diálogo Intercultural. Memorias del Primer Congreso Latinoamericano de Antropología Aplicada. Quito: Abya-Yala.

Cucurella, L. (2001). Sistematización de la experiencia editorial de Abya Yala. (Tesis de licenciatura de Comunicación Social). Quito: UPS.

Eguiguren, A. (2011). La esperanza es lo último que se pierde. Prácticas profesionales antropológicas en el Ecuador. En: La Arqueología y la Antropología en el Ecuador. Escenarios, retos y perspectivas Quito: Abya-Yala.

García, F. (2011). La construcción del pensamiento antropológico ecuatoriano: derroteros y perspectivas. Alteridades, 41 . 
Guerrero, P. (2011). Por una Antropología del corazonar comprometida con la vida. En: La Arqueología y la Antropología en el Ecuador. Escenarios, retos y perspectivas. Quito: Abya-Yala.

Guerrero, P., Ferraro, E., y Hermosa, H. (2016). El trabajo antropológico. Miradas teóricas, metodológicas, etnográficas y experiencias desde la vida. Quito: Abya-Yala/UPS.

Herrera, L. (2011). La Antropología Aplicada como parte de los procesos de transformación social. En: La Arqueología y la Antropología en el Ecuador. Escenarios, retos y perspectivas. Quito: Abya-Yala.

Jimeno, M., y Arias, D. (2011). La enseñanza de antropólogos en Colombia: una antropología ciudadana. Alteridades, 21.

Juncosa, J. (2012). Las antropologías de los antropólogos más allá de la academia. Universitas, 17. Quito: Editorial Universitaria Abya-Yala/UPS.

Krotz, E. (1993). La producción de la Antropología en el Sur: características, perspectivas, interrogantes. Alteridades, 6.

(2007). Las antropologías latinoamericanas como segundas: situaciones y retos. II Congreso Ecuatoriano de Antropología y Arqueología. Balance de la última década: Aportes, Retos y nuevos temas. Tomo I. Quito. Abya-Yala.

Larrea, A. M. (2011). La Antropología en los escenarios estatal de trabajo. En: La Arqueología y la Antropología en el Ecuador. Escenarios, retos y perspectivas. Quito: Abya-Yala.

Vázquez, H. (1993). La crisis de los paradigmas teóricos en Antropología sociocultural y sus derivaciones en la construcción de la disciplina en los países periféricos. Alteridades, 6 .

Web

https://www.iucn.org/es/content/cuando-la-antropología-también-es-política

\section{Entrevistas}

Entrevista con Daniela Fuentes, antropóloga, Subsecretaria del Ministerio de Cultura. Quito, 24 de noviembre de 2014.

Entrevista con P. Antonio D’Agostino, antropólogo, sacerdote Comboniano, trabaja con grupos afrodescendientes en barrios marginales de Guayaquil. Quito, 25 de octubre de 2014. 
Entrevista con Daniela Ochoa, antropóloga, docente de la Carrera de Antropología Aplicada de la Universidad Politécnica Salesiana. Quito, 18 de diciembre de 2014.

Entrevista con José Chalá, antropólogo, afrochoteño, Consultor y funcionario público. Quito, 25 de octubre de 2014.

Entrevista con Fernando García, antropólogo, docente de la FLACSO. Quito, 10 de noviembre de 2014.

Entrevista con Moisés Arcos, director de la escuela Nina Pacha con pedagogía Waldorf. Quito, 6 de septiembre de 2014.

Entrevista con Nelly Guevara, antropóloga, sanadora. Quito, 24 de noviembre de 2014.

Fecha de recepción: 5/12/2016; fecha de aceptación: 12/05/2017;

fecha de publicación: 30/06/2017 